\title{
Environmental Education in Guangzhou in the People's Republic of China: Global theme, politically determined?
}

\author{
Francis Wong Bing Kwan \& Philip Stimpson The University of Hong Kong \\ Environmental Education Research 7 (4) 397-412
}

SUMMARY

\section{Introduction}

Environmental education is a global concept developed in a time of social, economic and ecological globalisation. While environmental education programmes around the world share common aims generally based on UNESCO recommendations from various conferences over the last 25 years, they often differ in focus as a consequence of the environmental, historical, socio-political and educational systems in which they develop. This paper is concerned with environmental education in Guangzhou in the people's Republic of China and the context variables that have led to the present character of environmental education.

The framework is based on a social constructivist view of curriculum (Lawton, 1978; Print, 1993; Marsh \& Willis, 1995) and that different social contexts and beliefs give rise to differing curricular conceptions. Robertson \& Krugly-Smolska (1997) in a review of different conceptions of environmental education in the literature differentiated six views or perspectives: (1) utilitarian; (2) aesthetic; (3) ecological; (4) ethical; (5) deep ecological [or Gaian] in a combination of (3) and (4); and (6) the socially critical. It would, of course, be simplistic not to recognise that these are more properly dimensions and as such more than one is likely to be present in any situation. Nevertheless, the different conceptions form a useful basis for analysing and classifying environmental education in Guangzhou.

The paper is in three parts. The first outlines the existing nature of environmental education in Guangzhou and provides essential background. The second describes the methods used in the study. The third and major part of the paper provides an analysis of interview and documentary data and a discussion of themes in the environmental curriculum history of EE in Guangzhou.

\section{Environmental Education in Guangzhou}

Guangzhou, with a population of over 10 million, is one of the two major cities of southern China alongside Hong Kong. It is the provincial capital of Guangdong and the unofficial historical "southern capital" of China. It is lies at the northern end of a rapidly expanding industrial belt that runs down the Pearl River Delta to Hong Kong. As with all cities and regions of the PRC, it follows central government policies but, in particular following Deng's 'Open Door' policy, it is allowed some independence and develops its own versions of centrally defined curricula. 
The goals of EE in Guangzhou are set out in GEPPEC (1990). Five aims are promoted: (i) knowledge of environmental protection as a national policy; (ii) understanding that the environment is a part of the resources of China; (iii) awareness that environment implies certain values; (iv) awareness that environmental protection is a form of social ethics; and (v) knowledge that environmental protection is controlled by legislation. As Wong (1995) remarked, these look to:

...there should be an integration of science and sentiment. Learning should seek to develop a love for nature, rare species and the landscape...

teaching should concentrate on:

the protection of the environment and the well being of the public and explore the integrative use of resources and concepts of reuse. The aim is to help achieve a unity between economic effectiveness, social effectiveness and environmental effectiveness. (Wong, 1995, p.102)

Within the rhetoric of the PRC, these aims broadly follow an UNESCO worldview.

Objectives (Table 1) are at three levels. Those at school level being largely involved with fostering environmental consciousness (Level l) and awareness (Level ll). A linear notion of behaviour change is expressed. The document sets out the knowledge about the environment and the attitudes that pupils should acquire. The intent is that an environmental dimension is infused into and integrated with existing subjects in the mandatory school curriculum. (There have been calls for free-standing environmental studies courses that secondary school students could elect to take but these have gone unheeded.) EE is better developed in the primary schools than the secondary schools. In the former, it is mainly taught through geography and nature study (Jiang, 1994). In junior high schools the main approach is through integration with biology and geography in the main.

There are also informal, extra-curricular activities which emphasis the application of environmental understanding through industrial visits and school greening programmes. Outside the formal school sector, environmental education is conducted through activities such as community propaganda activities in which education, cultural entertainment -for example dance- and propaganda are blended together (Kwan and Lidstone, 1997).

Table 1 Objectives for Environmental Education in Guangzhou. 


\section{Level 1 To raise environmental consciousness}

(i) To learn basic environmental science, concepts of environmental protection and ecological balance.

(ii) To learn the dialectic relationship between people and environment, economic development and environmental protection. To understand the synchronisation of economic development, town-village development and environmental development.

(iii) To learn about the damage to the present and future generations caused by environmental pollution and ecological balance.

(iv) To learn that environmental protection enterprise is an important component in China's socialist modernisation.

\section{Level 11 To raise environmental awareness}

(i) To develop responsibility for environmental protection. Environmental protection should be regarded as social ethic.

(ii) To develop students' self-consciousness of environmental behaviour and good habits.

(iii) To develop students' enthusiasm in environmental protection including promotion and propaganda work.

(iv) To develop a sense of struggle against environmental damage and breaches of environmental law.

\section{Level 111 To raise environmental skills}

(I) To understand the parameters and characteristics of the environment and be able to evaluate the environment.

(ii) To understand environmental management measures and be able to identify environmental problems.

(iii) To understand the basic directions of environmental protection, policies, legislation and skills and be able to promote consistency of environmental behaviour.

(iv) To understand the whole picture of local and national environment and be able to mobilise and organise the public and local departments to launch environmental protection work.

Source: Guangzhou Environmental Protection Propaganda and Education Centre (1990)

\section{Method}

The study used a grounded theory methodology (Glaser and Strauss, 19xx) within an overall ethnographic approach. One of the researchers periodically visited Guangzhou over four years becoming part of the curriculum development scene in EE, interviewing participants in environmental education and collecting documentary evidence. The researcher sought to become immersed in the concerns of people involved in developing and teaching EE. Much of the research was involved with 'locating central figures, building rapport, watching, listening and learning'. The aim was to uncover the factors that the environmental workers in Guangzhou saw as determining what went on and to provide representations as descriptive accounts.

Interviews were conducted with 20 cadres (government officials), 8 principals and vice-principals, 30 teachers and 10 tertiary teachers. In general, these interviews, which are more accurately described as conversations, were not tape-recorded. This is not readily accepted in the PRC and if used informants would usually only repeat official statement. Instead data were nearly all based on field notes made during or immediately after meetings in which key comments were recalled. These were subsequently translated from Cantonese or Putonghua into English, the aim being to retain meaning rather than provide a verbatim translation. Key comments in the interview were recalled and subsequently translated from Putonghua or Cantonese into English with the aim of retaining meaning rather than verbatim translation. The notes were read numerous times to illicit key ideas which could then be tested in subsequent interviews. By this process of constant comparison, conceptual categories representing ideas about the determinants of EE in Guangzhou were defined and key themes identified. 


\section{Findings}

From the interview and documentary data, there emerged six, often interdependent, themes that help to explain the particular form that environmental education has taken in Guangzhou. These are:

1. EE as a response to environmental degradation and practical needs of society

2. EE as a knowledge focused area of scientific learning in the national interest

3. EE as a field of study with Chinese characteristics

4. EE as a political tool and an element in national propaganda

5. EE as an administratively led and centrally controlled innovation

6. EE as a field of study in conflict with mainstream education

\section{EE as a Response to Environmental Degradation and the Practical Needs of Society}

The need for environmental education in Guangzhou came from the serious environmental deterioration that the city and the surrounding are faced as a result of uncontrolled industrialisation. The problems are well documented by Edmonds (1997) based on data from the Guangzhou Environmental Protection Bureau. Environmental degradation is well recognised in Guangzhou. A cadre interviewed commented:

\footnotetext{
Guangzhou has many industrial activities. They consume large amounts of energy, hence there are great pollution problems (Cadre L).

Forty years ago when I was a child looking down from the mountain onto the city of Guangzhou, I could clearly see houses, roads and fields but now a layer of yellow smoke obscures the whole city (R).
}

However, the overall perspective was often one of environmental deterioration as a factor in economic development. A number of teachers took this up in a classroom context. A typical message being transmitted is illustrated by the following classroom comment:

The significance of environmental education is critically dependent on the economic effectiveness generated (Teacher T).

Cadre L continued:

Economic development in Guangzhou has been rapid and it provides the material foundation for environmental protection. 
The message is that industrialisation has brought about environmental problems but has generated the financial capital to develop preventative and remedial programmes.

The government has invested 40 billion yuan (about US\$5billion) in city and environmental infrastructure. The following actions have become government policies: firstly, the introduction of comprehensive urban planning; secondly, the inclusion of environmental protection activities and thirdly, environmental engineering (Cadre L).

Environmental education is a part of the second, environmental protection activities. Its context, however, seems more to do with sustained economic development than ecologically sustainable development.

The methods used to solve the problems are: firstly, to continue the open policy; secondly, economic reform; and, thirdly, to strengthen management (Cadre L).

This paralleled a comment in the editorial of the Chinese Editorial Press.

Since the dissemination of the open policy, related work in environmental protection in our country has centred around economic development and has explored an environmental protection path with Chinese characteristics.... By synchronizing planning, implementation and development, we actualize economic, social and environmental effectiveness. We carried out three policies to strengthen environmental management. These are: 'prevention comes first', 'those who pollute must handle the problem' and 'who explore who protect??'.... Only by fastening on economic growth can we strengthen the country, eliminate poverty and improve the material and cultural life of the people.

'With Chinese characteristics' means have consideration of the context of the PRC, its need for development and its socio-political institutions and processes. (This last point we will return to in a separate theme.) The Guangzhou Environmental Protection Propaganda and Education Committee (GEPPEC) also noted that environmental education should emphasise:

....the environmental problems of cities and industries; education should focus on environmental planning and management (GEPPEC, 1990).

The perspective is practical and technocratic rather than coming out of any ethical position vis a vis the inherent value of ecosystem maintenance.

2. EE as a Knowledge Focused Area of Scientific Learning in the National Interest 
As elsewhere in the PRC, EE in Guangzhou concentrates on knowledge of environmental significance related to established disciplines. There is an emphasis on a 'science' perspective whether it is taught through biology, a major avenue for EE, or geography, the other main route. The scientific knowledge perspective can be traced back to the adoption of the former Soviet Union model of educational thinking which was highly technological. Today, the PRC still holds a firm belief that science should play a major role. Thus, in Guangzhou, environmental science is often equated with environmental education and vice versa.

The GEPPC talked about 'environmental protection science' for the general public as well as pre-schools, primary schools, secondary schools and tertiary education. A teacher (Y), who was also a writer on environmental education, commented:

The success or failure of environmental work in China in the coming century depends on peoples' environmental consciousness. The main curriculum for secondary school environmental education should integrate compulsory subjects and moral education and should focus on the foundations of environmental science.

The focus is on environmental science in the national interest.

Environmental problems touch on all aspects of society and environmental science is an interdisciplinary science.....Environmental education starts from protecting and improving the living environment and ecological environment focusing on the environmental problems of cities and industries.

At the same time there is a strong focus on knowledge rather than attitudes and skills. A teacher (P), talking about how content was selected in the secondary school commented that:

Selection of content [from the subject texts which integrated environmental education] was mainly through the experience of EE educators who are mainly geography and biology teachers...Selection was based on that provided in the textbooks.

The textbooks were all important, Their focus became the classroom focus. Analysis of the texts showed that, of the twenty-nine chapters in the geography text, twenty-six emphasised factual knowledge about the environment and a cognitive focus. The three remaining were on 'the use of resources to protect the environment', 'natural resources and their protection' and 'man and the environment' and contained an affective element. A similar patter was apparent in the biological text.

Teachers, however, are not uncritical of this.

Environmental education in Guangzhou should include, firstly, the national context; secondly, quality education and then, thirdly, develop into a separate area of study...By quality education students should speak the truth, build appropriate values and develop strong will power.

There is concern about the lack of a strong component that emphasises environmental attitudes and values. 


\section{EE as a field of study with Chinese characteristics}

'Environmental education with Chinese characteristics' was referred to in the first theme concerning understanding the need for environmental protection and was a recurring element in many discussions of EE between environmental workers in the mainland and people from overseas in particular from the West. The 'Four Modernisations' in the period since the 1970s have seen an aim to modernise by importing technology and expertise while at the same time avoiding social change that might lead to political instability (Chan, 1992). In education, there was apparent in the selective adoption and adaption of western ideas into socialist culture. Whatever the changes, maintaining Chinese characteristics is a central element and Gu (1992) argues environmental education is no exception.

Selectivity within a Chinese context was well illustrated in Guangzhou when the researchers were working there. In 1993, the Guangzhou Municipal Government was enthusiastic to organise an international conference on EE in order to bring in expertise from overseas. This they did in 1994 but were selective in the sorts of information and ideas that could be included in the meeting. What was acceptable in the West was shown in Guangzhou to be not always acceptable in China. There was a perceived need to maintain a form of environmental education consistent with official lines. It was as Deng Xio peng had commented earlier about a market economy replacing a planned economy:

We tread the path of socialism with Chinese characteristics.

Statements from leaders, such as this, adopt much greater significance than in the West and are often taken up outside the original context in an outward show of national pride and support for the leadership.

....A few statements [from leaders] mean much. In Guangzhou instructions [from central government] are given through administrative meetings where leaders present speeches and seminars where papers are exchanged.

Following the leadership and thus, by definition, maintaining Chinese characteristics in any activity is the norm and a means of demonstrating loyalty. Thus, teacher (Z) echoed Deng and expressed acceptance of his ideas.

I think education about Chinese characteristics should be built into environmental education. We have a reference book called 'Education about Chinese characteristics' and it provides a background to understand China and thus EE.

What the teacher was alluding to were Chinese characteristics of collectivity, mass mobilisation, cultural heritage, population and ethnic diversity. 'With Chinese characteristics' is a code for 'Chinese socialist principles'. It goes further, however, in that, within socialism, it expresses patriotism, nationalism and self-pride.

\section{EE as a political tool and an element of propaganda.}

School staff seemed wary of any political stance. Politics was viewed sensitive being involved, as they saw it or feared, with criticism of the government. Politics seemed synonymous with opposition and therefore unacceptable. In a conversation between one of the researchers and a vice-principal of a school, the latter asked about the title of the paper that the researcher was going to present in Hong Kong/ On being told that it was about the political dimensions of environmental education, the vice-principal declared:

I don't think that environmental education should have any political dimension. The title of the paper is hostile to us. It challenges our political system.

Political analysis was seen as political criticism and safer if avoided. Indeed there were strong beliefs in the rightness of the system among older people. 
We were all brought up 'under the red flag'. We tasted all the bitterness. The present generation because of the poor lifestyle [it adopts] cannot pick up the relay rod (Teacher Z).

Being brought up 'under the red flag' is a reference to the hardships of the early days of the PRC and firmness of belief in the Chinese Communist Party and its policies. Yet to argue that environmental education in Guangzhou is apolitical is to miss the point. Rather it is that political positions conflicting with prescribed views of the leadership are unacceptable. Views consistent with the prevailing party-line, and hence implicitly political are not only acceptable but desirable and required.

Environmental education programmes were viewed as an explicit means to implement government environmental protection policies at national or provincial or, as in the case of Guangzhou, city level. Education and propaganda became synonymous with each other.

In environmental education work, we seek to promulgate environmental protection laws through education [in order to spread knowledge of] methods of environmental assessment and [to] enforce implementation through vertical and horizontal relationships [i.e. down through the administrative hierarchy and across the general public] (Cadre L).

Propaganda in the PRC does not have the negative connotations that it often assumes in the West. The Guangzhou Environmental Protection Propaganda and Education Centre (GEPPEC) would be, in Western terms, an information or public relations centre. The GEPPEC is there mobilise the public to respond to general campaigns a process that is seen in the PRC as a key strategy of the Chinese Communist Party (Guangzhou Environmental Press, 1994).

Proper development of environmental education depends on administrative leaders in places such as government departments and on school principals. Environmental protection depends on propaganda education both to start it up and as it develops. In conclusion, propaganda comes first; it is public opinion, education is the basis. (Huanijing Kexue, 1993, 2-5)

Zhou, a key political leader in the State Education Committee (the central ministry of education in Beijing) viewed environmental education as

Interest in global environmental questions and perspectives has, in part, to be viewed in a political context. Academics and environmental workers in Guangzhou are aware of the importance of a global perspective to solving environmental problems. However, at the same time, politically China seeks international credibility and recognition so that it can take the position in the world it feels it should have. Being a part of the global environmental forum is one way of expressing this. The political issue is, of course, primarily one for high level officials but, as explained earlier, there is a tendency for ideas if they come from the leadership to be taken on board generally. Thus, when the conference referred to earlier was being discussed with one of the researchers, there was the impression from the cadre interviewed that such an event was welcomed because it could help bring China into the international arena and fulfill the desire for a global position in EE.

The idea of organising an international conference next year in Guangzhou will be a great event for us....our development, particularly in EE, will step up onto a higher platform. Chief cadre L asked me to get hold of you and make the conference a reality.

It would be wrong to overplay this. It is not to suggest a cold cynicism but there was the feeling that political opportunities were not to be missed.

Participation in global environmental decisions was, however, recognised as bringing with it responsibilities and this perhaps inevitably carried with it new perspectives. A Cadre (F) in Guangzhou noted:

After the Premier Li Peng had participated in the Rio Summit Meeting in 1992, he promised to implement policies of environmental protection in China. He proclaimed, 'What we Chinese had said are promises. They [environmental measures] will definitely be carried out. After this, some ideas about sustainable development started to enter China. In the past, people in Guangzhou talked 
about the fact that the economy and environmental protection should be synchronized. But now, intra and intergenerational equity starts to appear in leaders' speeches.

Environmental education in Guangzhou is left with a dilemma, a balancing act, between maintaining a Chinese position which upholds socialist and national desires on the one hand and, on the other, meeting international agreements which may, in one way or another, be in conflict.

\section{EE as an administratively led and centrally controlled innovation}

Education in the PRC is highly centralised (Leung, 1991) and to a large extent has the aim of facilitating economic development within a socialist Chinese culture. Syllabi are national with regional adaptions largely at the Provincial level. Textbooks are centrally produced at either national or Provincial level. Guangdong has its variant. Curricula are academic-rationalist and instrumentalist in character rather than interpretive or socially critical. Education in schools follows a common pattern throughout the country with the exception of the Special Administrative Areas. There are six years of primary education followed by three of junior high school (Middle School) and, for the more able, three years of senior high school. There is, however, considerable variation in educational provision. This is not the least between the urban and rural areas. Even within a city, like Guangzhou, there are substantial differences between the few elite Key Point schools, which are highly selective, and other middle schools. Teaching styles are generally formal with a focus on exposition and testing. The text-books, which in the secondary sector tend to be discipline oriented in their treatment, are usually followed closely. The curricular and resource limitations present are recognised and efforts are being made to reform the situation, particularly in cities such as Guangzhou although progress across the board is slow.

In the promotion of environmental education in Guangzhou curriculum development is orchestrated by government cadres even though details are fleshed out by committees involving secondary school teachers and professionals, such as lawyers, alongside officials.

Environmental education in Guangzhou is mainly developed by the Environmental Education Professional Committee, the EEPC. The committee is an NGO and comprises school chairmen of various school subjects and other professional such as lawyers and university academics. The Guangzhou Environmental Science Association, the GESA, supports the committee administratively (Vice-principal L).

There are, however, clear definitions of the roles and responsibilities of organisations. Cadre F explained:

The Guangzhou Environmental Science Association, the GESA, is a statutory body affiliated to the Guangzhou Environmental Protection Bureau which is a [provincial] government department The EEPC is administered by the GESA although the EEPC claims to be a non-governmental organisation. The managing director of GESA is the Director of the Environmental Protection Bureau (Cadre F).

Organisations and committees like the GESA act as communication bridges between the public and the government. The Cadre above described them as acting as a 'wisdom tank' for the government. There is the feeling, however, somewhat akin to a puppet being played by the administration. Grassroots classroom decisions are largely restricted to how the content in the official textbooks should be presented. Nearly all environmental education activities outside mainstream schooling such as, for example, an essay competition or collaboration with Hong Kong environmental educators in a summer camp require permission of the Environmental Protection Bureau. 


\section{EE as a field of study in conflict with mainstream education}

At the system level the vital role of environmental education is accepted. The Deputy Director of the Education Bureau in Guangzhou commented:

Environmental education is a component of school education. It is indispensable $n$ improving the ethical and intellectual development of students. All schools need to include EE in their school reform.

Teachers involved in environmental education were equally certain of its place in the school curriculum.

...In the long run environmental education should be made an important area of study which occupies a place in the timetable. Then EE could be made a means to assess schools. Emphasis on environmental education would then be greatly improved (Teacher P).

While positive in one sense, it is negative in another in alluding to the marginal position of EE outside the timetable and the assessment system. The peripheral position of EE and people's attitudes to EE was remarked on by a student-teacher:

Whenever there are environmental education activities, it is just like a gust of wind. People take part in the activities for the sake of the activities. After that people returned to their over-consuming behaviour.

She might also have remarked that teachers returned to their focus on high-stakes traditional subjects, or traditional content within those subjects, that provide public examination success, access to the next stage of education and ultimately a well paid job. Indeed, geography and biology were the most frequent avenues for EE because their traditional content offered a considerable match and thus did not require major curricular or pedagogic change in the eyes of teachers.

The low stakes of environmental education within most Guangzhou school placed it in a weak position when competing for resources. Despite the fact that the Guangzhou Municipal Government understood the need to promote environmental education and provided some support, lack of funding was perceived as posing a problem in the implementation of EE. Commercial sponsorship helped.

In the recent dissemination of central instructions, there are ten items concerning he environment, one of which relates to environmental education. Local government responded actively. The Guangzhou Municipal Government spent nearly 200,000 yuan (about US\$15,000) on environmental protection and environmental education in 1992. In launching environmental education activities commercial organisations sponsored he work and had their names acknowledged on banners and pamphlets (Vice-Principal L).

However, despite public and private funding, resources are a major problem. In schools where funding was inadequate enthusiastic, environmentally committed teachers spent their own money from their meager salaries to provide resources. Less motivated teacher teachers were constrained from active involvement and a return to teaching to the textbook was legitimised.

\section{Conclusion}


EE in Guangzhou seeks to provide the essential environmental knowledge needed for the development of contemporary China. It is viewed as a minor element within the context of values education as a whole, the emphasis of which, as Lam (1993) also has pointed out, is strongly weighted towards the current state of the country and promoting pride in China. Environmental education in Guangzhou is primarily administered by the Environmental Protection Bureau but interpreted and planned by the GEPPEC and the ESA, at one level, and by teachers in the classroom at another. It emphasises cognitive aspects in practice and plays an important role as a propaganda tool to transmit the views of the leadership. The perspective is largely utilitarian but with ecological overtones. While the state of the environment and the nature of the education system have influenced the form environmental education takes in Guangzhou perhaps the over-riding force is political (Figure 1).

Insert fig 1

The aim is to integrate science and sentiment to develop a love and respect for nature and the environment but the focus is largely instrumental seeking directly to enhance involvement of the people in practising environmental protection. The desire is that young people will come to accept that environmental protection is something that involves everyone and that some personal sacrifice is needed for the common good of society and China. Theory and knowledge about the environment is to be integrated with conservation practices in and for the environment. However, knowledge, rather than problematic issues, is emphasised in what would be seen in global terms as a conventional view of EE. The environmental perspective of the curriculum is largely technocratic and accommodates the present socio-political system. A critical dimension is largely lacking. It looks to the adjustment of existing patterns of behaviour to maintain environmental sustainability (and perhaps social stability) without deflecting national and economic development. The tension between economic growth and environment, however, is recognised in the curriculum but the dilemma is not fully addressed.

\section{Notes on Contributors}

\section{REFERENCES}

CHAN (1992)

EDMONDS, R.L. (1996) Geography and Natural Resources, in: HOOK, B. (Ed) Guangdong: China's Promised Land (Oxford, Oxford University Press). 
Guangzhou Environmental Protection Propaganda and Education Centre (GEPPEC) (1990) Secondary School Environmental Education. Beijing, Chinese Environmental Science. (In Chinese).

GU (1992)

JIANG, X.L.(1994) The development of Environmental Education in China. Proceedings of the International Conference on Environmental Education "Environmental Education in the 21st Century", Guangzhou, 29-31, December, 1994, pp. 6-11.

KWAN, T.Y.L. \& LIDSTONE, J. (1997) Environmental Education in the People's Republic of China: a national policy, locally interpreted, Environmental Education Research, , pp. .

LAM, C.C (1993). Values education in secondary school geography in Guangzhou. International Research in Geographical and Environmental Education, 2 (2), 52-63.

LAWTON, D. (1978)

LEUNG, Y.M. (1991) Curriculum development in the People's Republic of China, in MARSH, C \& MORRIS, P. (Eds) Curriculum development in East Asia. London, Falmer Press.

MARSH, C. \& WILLIS, G. (1995) Curriculum: Alternative Approaches, Ongoing Issues, (Englewood Cliffs, New Jersey, Prentice Hall).

PRINT, (1993)

ROBERTSON, C. L. \& KRUGLY-SMOLSKA (1997) Gaps between Advocated practices and teaching Realities in Environmental Education, Environmental Education Research, 3, 3, pp. 311-326.

STRAUSS \& CORBIN (1990 ) Basics of Qualitative Research: Grounded Theory Procedures and Techniques, (London, Sage).

WONG, F.B.K. (1995) Rhetoric or reality - Environmental education in Guangzhou. International Research in Geographical and Environmental Education, 4, 2, pp.101-105. 
ENVIRONMENTAL FACTOR

- environmental deterioration with economic development

- low level of environmental awareness

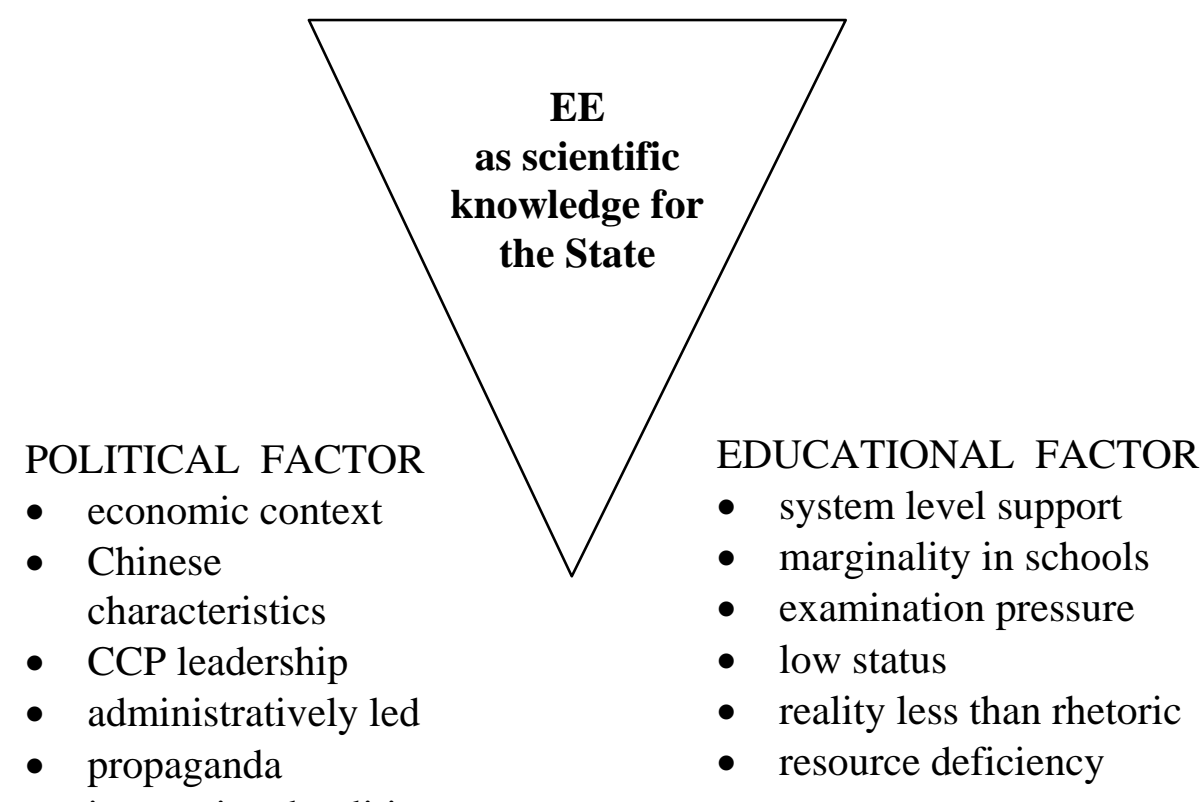

